\title{
The Application of Retrospective ECG Gated 320-MSCT Angiography in Diagnosis of Congenital Pulmonary Arterial Anomalies in Pediatrics
}

\author{
Nour Tawheed ${ }^{1, *}$, Amr Mohamed El-Badry ${ }^{1}$, Suzan Elhefnawy $^{2}$, Basma Samir Eldeeb ${ }^{1}$ \\ ${ }^{1}$ Department of Radiology, Faculty of Medicine, Tanta University, Tanta, Egypt \\ ${ }^{2}$ Department of Cardiology, Faculty of Medicine, Tanta University, Tanta, Egypt \\ Email address: \\ mowafyn@gmail.com (N. Tawheed), amr.elbadri@med.tanta.edu.eg (A. M. El-Badry), suzan.elhafnawi@med.tanta.edu.eg (S. Elhefnawy), \\ basma.eldeeb@med.tanta.edu.eg (B. S. Eldeeb) \\ ${ }^{*}$ Corresponding author
}

\section{To cite this article:}

Nour Tawheed, Amr Mohamed El-Badry, Suzan Elhefnawy, Basma Samir Eldeeb. The Application of Retrospective ECG Gated 320-MSCT Angiography in Diagnosis of Congenital Pulmonary Arterial Anomalies in Pediatrics. International Journal of Medical Imaging.

Vol. 9, No. 1, 2021, pp. 1-15. doi: 10.11648/j.ijmi.20210901.11

Received: December 15, 2020; Accepted: December 28, 2020; Published: January 4, 2021

\begin{abstract}
Congenital pulmonary arteries anomalies included a wide-ranged spectrum of pathology that is usually associated with other congenital heart diseases. These anomalies can be classified into several major categories, which show considerable overlap among those categories. The aim of this study is to evaluate the role of multi-slice computed tomography (MSCT) angiography in assessment of pulmonary arteries anomalies. This study included 76 patients ( 42 males and 34 females) with male to female ratio $55.2 \%$ to $44.7 \%$. The age of the patients ranged from 4 days to 15 years. The studied cases for pulmonary arteries anomalies were subclassified to anomalies of the caliber, origin and development (conotruncal anomalies). We compared MSCT findings with the data collected by cardiac catheterization and/or operation in 38 patients. 320-MSCT diagnosed cases of pulmonary arterial anomalies with $99 \%$ sensitivity, $99.8 \%$ specificity, $99 \%$ PPV, 99.8\% NPV and $93.4 \%$ accuracy. This study concluded that MSCT is a non-invasive imaging modality that has a significant value in the evaluation of the congenital pulmonary arteries anomalies and its associated extracardiac anomalies in pediatric patients as well as assessment of post-operative complications. It is superior to $\mathrm{ECHO}$ in evaluating the pulmonary artery anomalies specially the pulmonary artery branches which are obscured by aerated lung. Also, there is good outcome of the cases owing to early and accurate diagnosis of the cases and post-operative follow up.
\end{abstract}

Keywords: 320-MSCT, Pulmonary Artery, Congenital Pulmonary Arteries Anomalies, Congenital Heart Diseases, and Retrospective ECG Gated MSCT

\section{Introduction}

Congenital pulmonary artery anomalies are a broad spectrum of anomalies that usually are associated to other congenital heart diseases, the isolated anomalies of PAs are less common. They are present at birth, range from asymptomatic to severe symptoms that may cause cardiac death. They may be recognized early in infancy while others represented in adulthood. Its age of presentation depends on pulmonary blood flow restriction or plethora [1].

Pulmonary arterial anomalies are evaluated by multiple imaging modalities including Chest X-Ray (CXR), echocardiography (ECHO), magnetic resonance imaging (MRI) and computed tomography (CT) [2]. CXR is the initial simplest technique for imaging the heart with very low levels of radiation. It provides a wealth of information such as an abnormal cardiac silhouette, exclusion of cardiac malposition, evaluation of pulmonary vascularity. This will guide toward the need for further diagnostic cardiac imaging modalities [3]. Echo provides immediate high- resolution anatomical and physiological information with the advantage of being noninvasive, safe, low cost and wide availability. However, it is operator dependent, limited evaluation of extracardiac structures, and the image quality can be compromised in children who are uncooperative 
or if there is a poor acoustic window [4].

MSCT is an important modality in the evaluation of pediatric congenital heart diseases. CT scanning is an accurate, non-invasive imaging modality that evaluate cardiac, vascular, extracardiac structures also important in detection of post-operative complications. After contrast injection, the heart and vessels anatomy can be evaluated in detail [5]. The role of MSCT in the evaluation of intracardiac anomalies is better owing to the advances in CT scanners and ECG-gating techniques [6].

MSCT provide images with better temporal and spatial resolution, greater anatomic coverage, high quality of $2 \mathrm{D}$ and $3 \mathrm{D}$ reconstruction [7]. 3D reconstructions of vessels and the trachea will illustrate the complex anatomy in ways that can be understood easily and help the surgeon to decide the surgical strategy. CT facilitates accurate assessment of the central and peripheral pulmonary arteries while Echo is limited in the assessment of branch pulmonary arteries due to the presence of surrounding gas-containing lung [6].

Cardiac catheterization remains the gold standard for morphological and hemodynamic assessment. Compared with $\mathrm{CT}$, cardiac catheterization has a higher complication rate as it is invasive, larger volume of intravascular contrast material, more frequently requires general anesthesia, and high radiation dose exposure to the patient. Also, it can't evaluate extravascular structures such as the airway and lung parenchyma $[8,9]$.

Cardiac MRI has become an alternative, non-invasive and safe imaging modality for the investigation and diagnosis of CHD. It provides both anatomical and physiological information. However, its limitations include poorer spatial resolution, higher cost, contraindication in patients with pacemakers, and increased need for general anesthesia in younger children [4].

320-MSCT (Aquilion One, Toshiba, Japan) has one expanded 320-detector block along the z-axis. The 320-MSCT can cover $16 \mathrm{~cm}(0.5 \mathrm{~mm} \times 320$ detectors $)$ with an improved gantry rotation speed $(0.35 \mathrm{~s} /$ rotation $)$. The 320 -MSCT can scan the whole heart in $<1$ second $(0.35 / 2=0.185 \mathrm{~s}$ for half reconstruction) even in patients with an enlarged heart [10].

\section{Patients and Methods}

This study was carried on 76 patients (42 males and 34 females) with their age ranged from 4 days to 15 years at the period between February 2019 to September 2020.

Patients were referred from pediatric cardiology and cardio-thoracic departments with their echocardiographic reports with suspected or diagnosed pulmonary arterial anomalies and underwent MSCT angiography of the heart and great vessels to confirm the diagnosis or to answer specific anatomic questions.

Patients were selected according to the following inclusion and exclusion criteria:

\subsection{Inclusion Criteria}

This study included 76 patients known or strongly suspected to have pulmonary arterial anomalies with inconclusive echocardiographic findings.

\subsection{Exclusion Criteria}

The study ruled out patients with renal dysfunction (serum creatinine more than $1.5 \mathrm{mg} / \mathrm{dL}$ ) and serious allergy to iodinated contras media.

\subsection{Method}

\subsubsection{Every Patient Was Subjected to the Following}

1. Consultation with the referring physician was attempted before the study to discuss the clinical background of the case and delineate specific questions raised by the physician in order to understand the reason for referral and expectations of the physician from the study.

2. Review of echocardiographic findings.

3. Checking renal functions.

4. Proper history taking from the parents.

\subsubsection{Patient Preparation}

The Procedure was described to the parents with their reassurance.

Intravenous cannula was placed in right upper limb veins in (25 patients) and in the lower limb veins in (51 patients).

\subsubsection{Sedation}

64 patients were orally sedated by administration of chloral hydrate $(50-100 \mathrm{mg} / \mathrm{kg}$; maximum dose, $2000 \mathrm{mg})$ and 6 patients were sedated by IV midazolam $(0.05-0.1 \mathrm{mg} / \mathrm{kg}) .6$ older patients were responding to verbal reassurance and be able to completely suspend respiration.

\subsubsection{Assessment of Emergency Set}

1. Sphygmomanometer

2. Oxygen container with mask and extension tubing.

3. Emergency drugs such as adrenaline, used for severe hypotension or anti-histaminic for contrast reaction.

4. Facility to transfer the patient to the emergency room if uncontrolled complication developed.

\subsection{Technique of CT Examination}

\subsubsection{Data Acquisition}

1. Patients were scanned using 320-row multislice CT scanner (Aquilion One, Toshiba Medical Systems, Otawara, Japan), the patient lay supine on the CT table and a restrain was applied over the chest to minimize motion artifacts.

2. The patient was positioned in the iso-center of the table to ensure the heart lies of the gantry for optimal spatial resolution.

3. ECG electrodes were applied to chest wall after skin preparation with alcohol.

4. The intravenous (IV) line was connected, and saline test injection was done to ensure good IV access with no extravasation.

5. A scanogram (frontal \& lateral views) was obtained where the scan ranges from neck root down to the level of portal vein inferiorly. It was important to diagnose 
co-existing anomalous pulmonary venous return, vascular rings and situs abnormalities.

6. Non ionic, non-diluted contrast material (Ultravist 370 , Schering AG, Germany or Omnipaque 350, Nycomed, Amersham) was injected through the inserted IV cannula in 45 and 31 patients respectively with dose $2 \mathrm{ml} / \mathrm{kg}$ and flow rate $1-1.5 \mathrm{ml} / \mathrm{sec}$ increased to $3 \mathrm{ml} / \mathrm{sec}$ in older children followed by saline injection ( $1 \mathrm{ml} / \mathrm{kg})$ immediately after the contrast injection to improve the contrast opacification and homogenicity.

7. Manual Bolus tracking was applied 10 to 15 seconds after contrast material injection (for upper limb venous line) and after 20 seconds (for lower limb venous line), the scan is initiated after opacification of both ventricles.

8. All scans were performed in a craniocaudal direction, with CT parameters adapted to the patient's weight. The patients were scanned using a single-phase retrospective ECG gated Computed tomography angiography (CTA) volume scan with a rotation time of $0.35 \mathrm{~s}$ and a tube voltage of $80 \mathrm{kV}$ increased to $100 \mathrm{kV}$ in 6 older patients. The tube current was automatically adjusted based on the size and shape of the individual patient

\subsubsection{Image Reconstruction and Post Processing}

By the end of examination, Full volumes were reconstructed in $0.5 \mathrm{~mm}$-thickness slice. Post-processing of MSCT scans was performed on a dedicated Vital Images workstation (Vitrea Fx, vital images, USA) to obtain multiplanar images in axial, sagittal and coronal planes, Also Maximum intensity projections (MIP), three-dimensional Volume rendering technique and Curved Multiplanar Reconstruction were obtained to display heart anomalies.

\subsection{Image Interpretation}

Images were interpreted guided by the anatomical and segmental approach and the results correlated then by Echo findings in all cases and surgery and/or catheter angiography findings were reviewed and compared to CTA findings in 38 patients.

\subsection{Radiation Dose Evaluation}

The dose-length product of each participant was recorded. The cardiac CTA effective dose was equal to the results of the dose-length product multiplied by the conversion factor. The specific dose length product conversion coefficients for infants were different for different age ranges: less than 4 months, conversion coefficient of $0.039 \mathrm{mSv} /(\mathrm{mGy}-\mathrm{cm}) ; 4$ months to 1 year of age, conversion coefficient of $0.026 \mathrm{mSv} /$ (mGy-cm); 1 year to 6 years, conversion coefficient of 0.018 $\mathrm{mSv} /(\mathrm{mGy}-\mathrm{cm})$; older than 6 years, conversion coefficient of 0.014 [11].

\subsection{Statistical Analysis}

All the data were entered into Excel sheet Microsoft Office Excel-2007 and analyzed statistically using SPSS Statistical Software (version 20.0.0: IBM Corp: Armonk, NY).
Qualitative data was presented using number and percentage. Quantative data presented as mean and standard deviation (SD). For categorical variables, Chi-square test was used for analysis. The level of significance was adopted at $p<0.05$. Mean value is the sum of all observations divided by the number of observations. Standard Deviation (SD) it measures the degree of scatter individual varieties around their mean, Sensitivity that is the capacity of the test to correctly identify diseased individuals in a population "true positive". The greater the sensitivity, the smaller the number of unidentified cases "false negatives", Specificity that is the capacity of the test to correctly exclude individuals who are free of the disease "true negatives". The greater the specificity, the fewer "false positives" will be included and Accuracy (Rate of Agreement=(True positives + True negatives) / Total tested $\mathrm{x}$ 100).

\section{Results}

This study included 76 patients (42 males and 34 females) with male to female ratio $55.2 \%$ to $44.7 \%$. The age of the patients ranged from 4 days to 15 years. The all pulmonary artery anomalies results that diagnosed by MSCT are correlated with TTE findings (all cases) and (38 cases) are correlated with surgical or catheter angiography findings. The studied cases for pulmonary arteries anomalies were subclassified to anomalies of the caliber, origin and development (conotruncal anomalies) (Table 1).

Table 1. Pulmonary artery anomalies detected by ECHO and MSCT in the studied cases.

\begin{tabular}{|c|c|c|c|c|}
\hline & \multicolumn{2}{|c|}{ ЕСНО } & \multicolumn{2}{|c|}{ MSCT } \\
\hline & No. & $\%$ & No. & $\%$ \\
\hline \multicolumn{5}{|l|}{ Abnormal caliber } \\
\hline \multicolumn{5}{|l|}{ Pulmonary stenosis } \\
\hline Subvalvular stenosis & 24 & 31.6 & 24 & 31.6 \\
\hline Valvular stenosis & 20 & 26.3 & 20 & 26.3 \\
\hline Supravalvular stenosis & 2 & 2.6 & 20 & 26.3 \\
\hline \multicolumn{5}{|l|}{ Pulmonary atresia } \\
\hline MPA atresia & 24 & 31.6 & 26 & 34.2 \\
\hline RPA \& LPA atresia & 0 & 0.0 & 0 & 0.0 \\
\hline \multicolumn{5}{|l|}{ Pulmonary hypoplasia } \\
\hline MPA hypoplasia & 10 & 13.1 & 10 & 13.1 \\
\hline RPA hypoplasia & 22 & 28.9 & 28 & 36.8 \\
\hline LPA hypoplasia & 20 & 26.3 & 26 & 34.2 \\
\hline \multicolumn{5}{|l|}{ Pulmonary dilatation } \\
\hline MPA dilatation & 22 & 23.9 & 24 & 31.5 \\
\hline RPA dilatation & 4 & 4.3 & 6 & 7.9 \\
\hline LPA dilatation & 6 & 6.5 & 8 & 10.5 \\
\hline \multicolumn{5}{|l|}{ Abnormal origin } \\
\hline Pulmonary sling & 0 & 0.0 & 2 & 2.6 \\
\hline \multicolumn{5}{|l|}{$\begin{array}{l}\text { Abnormal development } \\
\text { (Conotruncal anomalies) }\end{array}$} \\
\hline TOF & 22 & 28.9 & 22 & 28.9 \\
\hline D-TGA & 10 & 13.1 & 10 & 13.1 \\
\hline Congenitally corrected TGA & 4 & 5.3 & 4 & 5.3 \\
\hline Truncus arteriosus & 4 & 5.3 & 4 & 5.3 \\
\hline DORV & 4 & 5.3 & 4 & 5.3 \\
\hline
\end{tabular}

These findings were correlated with the ability of 
echocardiography examination of its diagnosis and its degree of certainty as a preoperative evaluation technique. In our study, the detected anomalies of the caliber were pulmonary atresia, pulmonary hypoplasia, pulmonary stenosis and pulmonary dilatation, anomalies of the origin were pulmonary sling and the anomalies of development of MPA (Conotruncal anomalies) were TOF, TGA, Congenitally corrected TGA, Truncus arteriosus and DORV.

Regarding pulmonary stenosis, it is subclassified into three types according to the level of stenosis and it includes subvalvular, valvular and supravalvular pulmonary stenosis. The most common type was the subvalvular type (31.5\%). Both MSCT and Echo displayed 100\% agreement in diagnosis of subvalvular and valvular stenosis. Echo missed detection of 18 cases of supravalvular pulmonary stenosis.

Regarding pulmonary atresia, MSCT detected 26 cases of MPA atresia (34.2\%) while ECHO misdiagnosed 2 cases of pulmonary atresia. Pulmonary atresia is classified as pulmonary atresia with Ventricular septal defect (PA-VSD) and pulmonary atresia with intact interventricular septum (PA-IVS). MSCT diagnosed pulmonary atresia with VSD in (24 cases, $92.3 \%$ ) and pulmonary atresia with IVS in ( 2 cases, $7.7 \%$ ). Echo missed the detection of 2 cases of pulmonary atresia with VSD.

Pulmonary atresia with VSD classified into 3 types (A, B and $C)$, most of the cases of pulmonary atresia-VSD were type A (20 cases, 83.3\%) and type B detected in (4 cases, 16.7\%).

Regarding pulmonary hypoplasia, MSCT reported MPA hypoplasia in 10 cases (13.1\%), RPA hypoplasia in 28 cases $(36.8 \%)$ and LPA hypoplasia in 26 cases $(34.2 \%)$ while ECHO missed diagnosis of 6 cases of RPA and LPA hypoplasia.

Regarding pulmonary dilation, MSCT detected 24 cases (31.5\%), 6 cases $(7.9 \%)$ and 8 cases $(10.5 \%)$ of MPA, RPA and LPA dilatation respectively. While ECHO missed detection of 2 cases of each type.

Regarding the abnormal origin, MSCT reported diagnosis of 2 cases of pulmonary sling $(2.6 \%)$ while ECHO missed detection of them.

Regarding the abnormal development (conotruncal anomalies), MSCT diagnosed 22 cases $(28.9 \%)$ of TOF, 10 cases $(13.1 \%)$ of D-TGA, 4 cases $(5.3 \%)$ of Congenitally corrected TGA, 4 cases $(5.3 \%)$ of Truncus arteriosus type I and 4 cases $(5.3 \%)$ of DORV. There was total agreement in diagnosis of conotruncal anomalies between ECHO and MSCT.

Out of the 76 cases, 36 cases of them had more than one type of pulmonary artery anomalies.

As regards the supravalvular pulmonary stenosis, it is classified to 4 types (I, II, III, IV), MSCT detected 20 cases of supra valvular pulmonary stenosis 18 cases of them (90\%) are type I and 2 cases are type III (10\%). Echo missed diagnosis of 18 cases of supra valvular pulmonary stenosis and diagnose only 2 cases of supravalvular stenosis of MPA. Chi square test revealed a statistically significant difference between both Echo, and MSCT in detection of supravalvular pulmonary artery stenosis $(\mathrm{p}=0.008)$.
In all cases of small sized main pulmonary artery or its two major branches ( $\mathrm{n}=46$ cases) McGoon ratio was calculated. Out of 46 cases, Mcgoons ratio was favorable in (32 cases, $69.6 \%$ ), so this group of patients were adequate for complete surgical repair.

Four cases showed combined arterial and venous pulmonary anomalies $(n=4)$, the first case of them showed TAPVR (supracardiac type) associated with pulmonary atresia, the second case showed truncus arteriosus type I associated with PAPVR to infradiaphragmatic IVC, the third one showed TAPVR (supracardiac type) associated with hypoplastic right upper lobe pulmonary artery, the fourth one is a case of TGA associated AVM.

The cases examined for aorto-pulmonary connections and they were subclassified into patent ductus arteriosus (PDA) and major aorto pulmonary collateral arteries (MAPCAs). These findings were correlated with the ability of Echo to delineate them as a preoperative evaluation technique. Our study entails 38 cases $(50 \%)$ of PDA and 10 cases $(13.1 \%)$ having MAPCAs. Only 32 cases of PDA were depicted by echocardiographic examination. Echocardiography failed to diagnose 6 cases of PDA and one case of ductus diverticulum. Echo also missed diagnosis of 8 cases of MAPCAs.

The intracardiac defects encountered within the study were classified into Atrial and ventricular septal defects. The most common ventricular septal defect (VSD) was subaortic VSD (32 cases) representing $42.1 \%$ of the studied cases. The most common atrial septal defect (ASD) was ostium secundum ASD (30 cases, 39.5\%).

CT could detect associated non-cardiac abnormalities which are frequently encountered in patients with congenital heart diseases as shown.

In this study, 32 cases showed patches of pulmonary consolidation. Hypoplastic right upper lobe of lung and horseshoe lung were detected once in association with a case of hypoplastic right upper lobe pulmonary artery and TAPVR. Tracheal compression and bronchial suis detected also once in a case of pulmonary sling. It also detected abnormal bronchial branching pattern in situs inversus, situs ambiguous cases and skeletal anomalies (vertebrae and ribs).

The CT scanner automatically estimated the absorbed radiation dose in the form of dose length product (DLP) (radiation dose for a predetermined scanned length). For transforming the DLP to effective radiation dose in milliSievert, it is agreed to multiply the DLP by conversion coefficient factor according to age. 76 MSCT examinations were done and the mean absorbed radiation dose was $91.79 \pm$ $88.45 \mathrm{mGy}$ per scan and the mean effective dose was $2.61 \pm$ $1.38 \mathrm{mSv}$.

Out of the 76 cases, we followed 38 cases of them as some cases died before the surgical intervention and others missed to be followed. We compared the ECHO and MSCT findings with the data collected by cardiac catheterization and/or operation. 320-MSCT diagnosed cases of pulmonary arterial anomalies with 99\% sensitivity, 99.8\% specificity, 99\% PPV, 99.8\% NPV and 93.4\% accuracy (table 2). 
Table 2. Agreement (sensitivity, specificity and accuracy) for operative data and MSCT in the studied cases of pulmonary artery anomalies (38 cases correlated with intervention data) and most of cases have more than one pulmonary artery anomalies (with 99 pulmonary arterial anomalies).

\begin{tabular}{|c|c|c|c|c|c|c|c|c|c|c|}
\hline \multirow{3}{*}{ Abnormal caliber } & \multirow{3}{*}{ Intervention } & \multicolumn{9}{|l|}{ MSCT } \\
\hline & & \multicolumn{2}{|l|}{ True } & \multicolumn{2}{|l|}{ False } & \multirow{2}{*}{ Sens. } & \multirow{2}{*}{ Spec. } & \multirow{2}{*}{ PPV } & \multirow{2}{*}{ NPV } & \multirow{2}{*}{ Acc. } \\
\hline & & positive & negative & positive & negative & & & & & \\
\hline Pulmonary stenosis & & & & & & & & & & \\
\hline -Subvalvular stenosis & 10 & 10 & 28 & 0 & 0 & 100.0 & 100.0 & 100.0 & 100.0 & 100.0 \\
\hline -Valvular stenosis & 7 & 7 & 31 & 0 & 0 & 100.0 & 100.0 & 100.0 & 100.0 & 100.0 \\
\hline $\begin{array}{l}\text { - MPA atresia with sizable } \\
\text { pulmonary arteries }\end{array}$ & 4 & 4 & 34 & 0 & 0 & 100.0 & 100.0 & 100.0 & 100.0 & 100.0 \\
\hline $\begin{array}{l}\text { - MPA atresia with confluent } \\
\text { hypoplastic pulmonary arteries }\end{array}$ & 7 & 7 & 30 & 1 & 0 & 100.0 & 96.8 & 87.5 & 100.0 & 97.4 \\
\hline $\begin{array}{l}\text { - RPA \& LPA atresia } \\
\text { Pulmonary hypoplasia }\end{array}$ & 0 & 0 & 0 & 0 & 0 & - & - & - & - & - \\
\hline -MPA hypoplasia & 5 & 5 & 33 & 0 & 0 & 100.0 & 100.0 & 100.0 & 100.0 & 100.0 \\
\hline -RPA hypoplasia & 11 & 11 & 27 & 0 & 0 & 100.0 & 100.0 & 100.0 & 100.0 & 100.0 \\
\hline $\begin{array}{l}\text {-LPA hypoplasia } \\
\text { Pulmonary dilatation }\end{array}$ & 10 & 10 & 28 & 0 & 0 & 100.0 & 100.0 & 100.0 & 100.0 & 100.0 \\
\hline -MPA dilatation & 10 & 10 & 28 & 0 & 0 & 100.0 & 100.0 & 100.0 & 100.0 & 100.0 \\
\hline -RPA dilatation & 3 & 3 & 35 & 0 & 0 & 100.0 & 100.0 & 100.0 & 100.0 & 100.0 \\
\hline $\begin{array}{l}\text {-LPA dilatation } \\
\text { Abnormal origin }\end{array}$ & 4 & 4 & 34 & 0 & 0 & 100.0 & 100.0 & 100.0 & 100.0 & 100.0 \\
\hline $\begin{array}{l}\text { Pulmonary sling } \\
\text { Abnormal development } \\
\text { (Conotruncal anomalies) }\end{array}$ & 1 & 1 & 37 & 0 & 0 & 100.0 & 100.0 & 100.0 & 100.0 & 100.0 \\
\hline$-\mathrm{TOF}$ & 8 & 8 & 30 & 0 & 0 & 100.0 & 100.0 & 100.0 & 100.0 & 100.0 \\
\hline -D-TGA & 3 & 3 & 35 & 0 & 0 & 100.0 & 100.0 & 100.0 & 100.0 & 100.0 \\
\hline -Congenitally corrected TGA & 2 & 2 & 36 & 0 & 0 & 100.0 & 100.0 & 100.0 & 100.0 & 100.0 \\
\hline -Truncus arteriosus & 2 & 2 & 36 & 0 & 0 & 100.0 & 100.0 & 100.0 & 100.0 & 100.0 \\
\hline -DORV & 1 & 1 & 37 & 0 & 0 & 100.0 & 100.0 & 100.0 & 100.0 & 100.0 \\
\hline
\end{tabular}

\section{Cases}

\subsection{Case 1}

Female child aged 2 years presented by with cyanosis, failure to thrive and recurrent chest infection
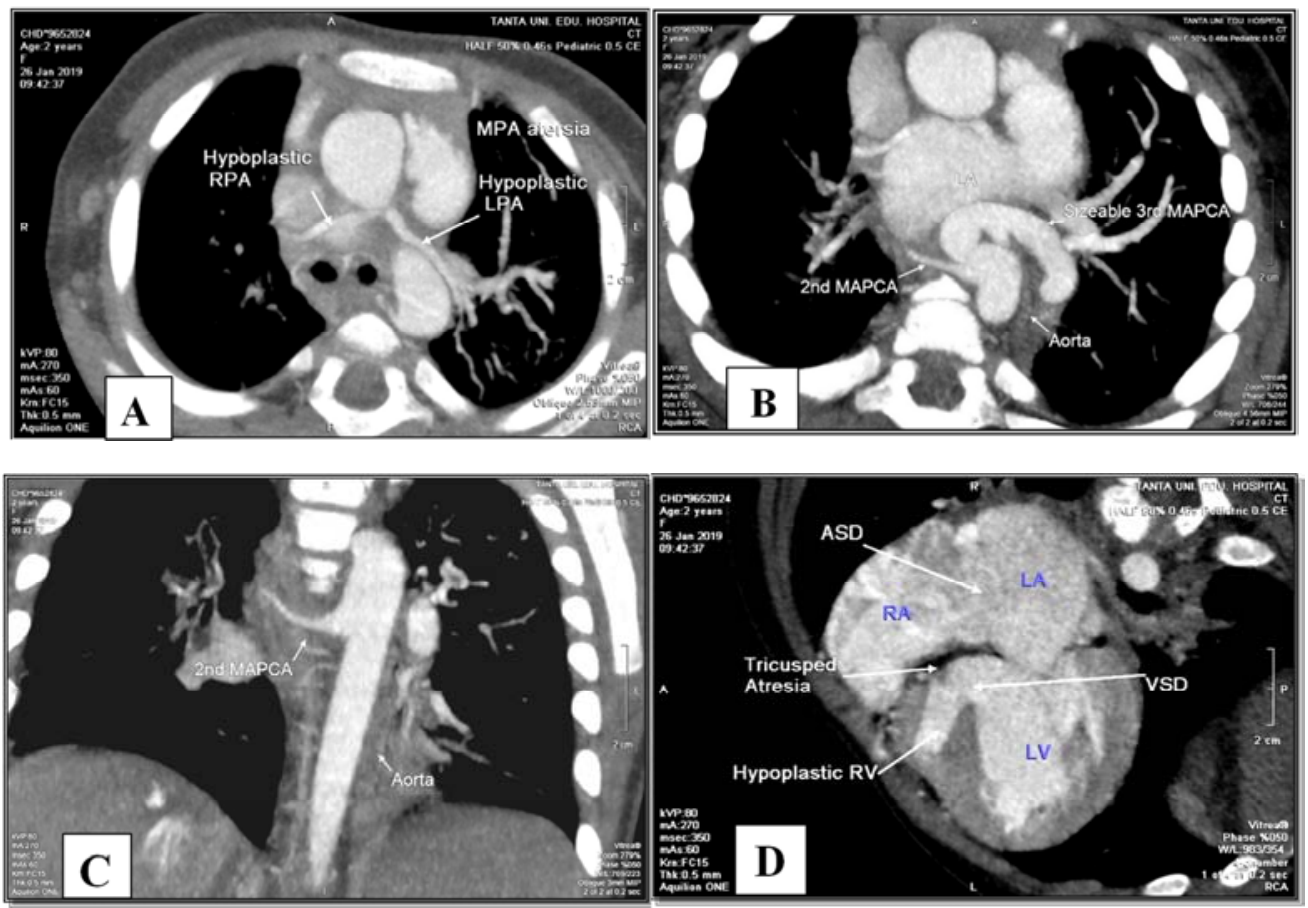

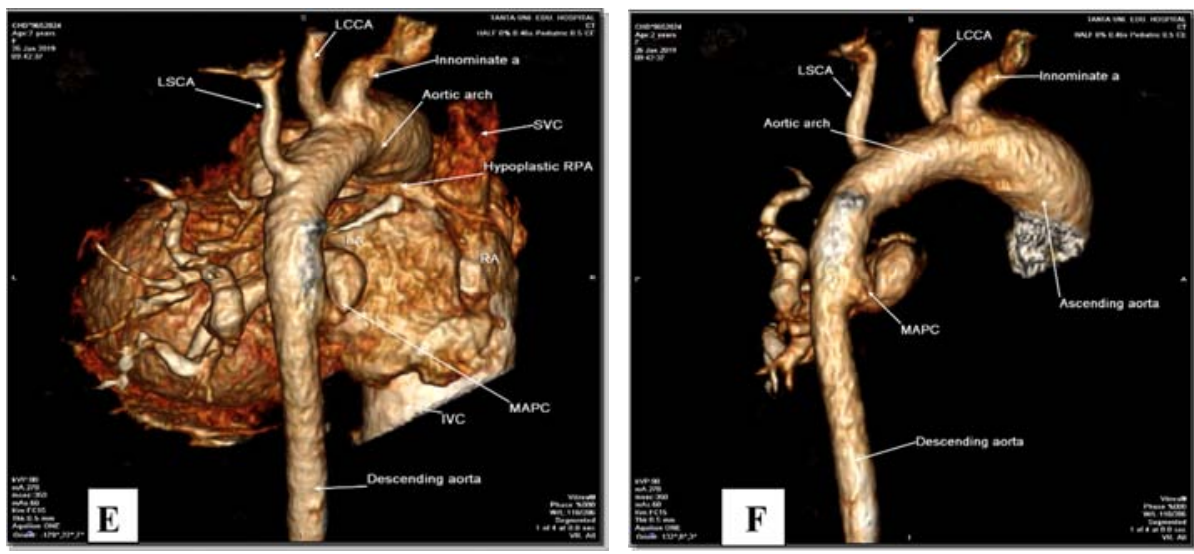

Figure 1. A case of pulmonary atresia with MAPCAs dependent pulmonary circulation (type B).

(A) Axial MIP image showing MPA atresia with confluent hypoplastic RPA \& LPA.

(B) Oblique MIP image showing the second and third MAPCA that arises from the descending aorta.

(C) MPR image showed the second MAPCA arising from the descending aorta and supplies the right lower lung lobe.

(D) Oblique 4-Chamber view showing dilated both atria and left ventricle, hypoplastic right ventricle, tricuspid atresia, large ostium secundum ASD and perimembranous VSD.

(E) VR image posterior view showing MAPCA, hypoplastic pulmonary arteries, aortic arch with its branches and descending aorta.

(F) VR image showing MAPCAs that arise form descending aorta.

\subsection{Case 2}

Female child aged 1 year presented with cyanosis and poor feeding.
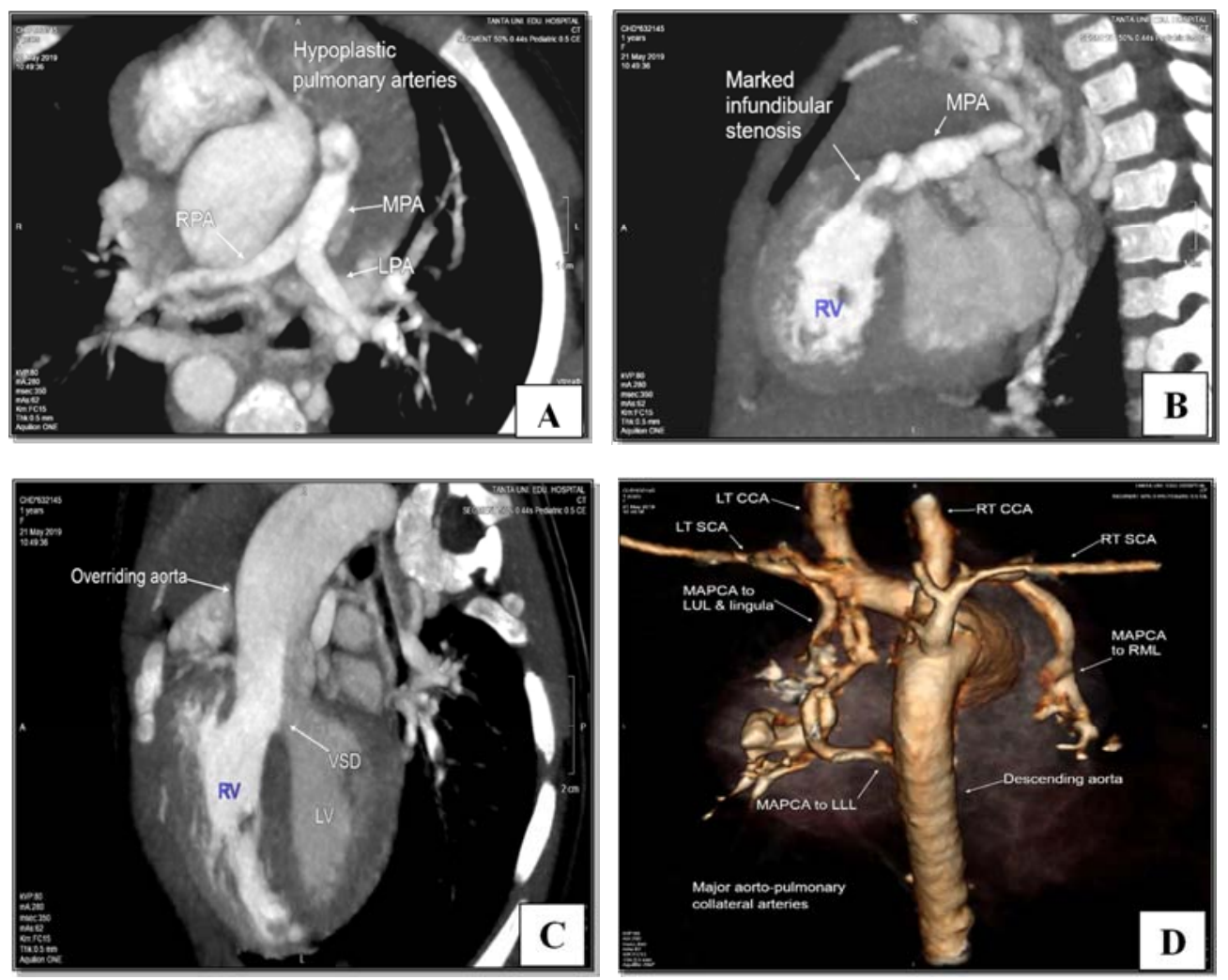

Figure 2. A case of Fallot's tetralogy with hypoplastic pulmonary arteries.

(A): Axial MIP image showing hypoplastic MPA, RPA \& LPA.

(B) MPR sagittal image showing marked infundibular stenosis with hypoplastic MPA.

(C) Oblique reformatted image showing Overriding aorta with ventricular septal defect (VSD) and dilated ascending aorta.

(D) VR image posterior view showing three MAPCAs, the $1^{\text {st }}$ MAPCA arises from the right subclavian artery which supplies the right middle lung lobe, $2^{\text {nd }}$ MAPCA arises from left subclavian artery supplies branches to left upper lobe and lingula and the $3^{\text {rd }}$ MAPCA arises from the descending aorta then supply branches to left lower lung lobe. 


\subsection{Case 3}

Female child aged 2 months presented with cyanosis and dyspnea.
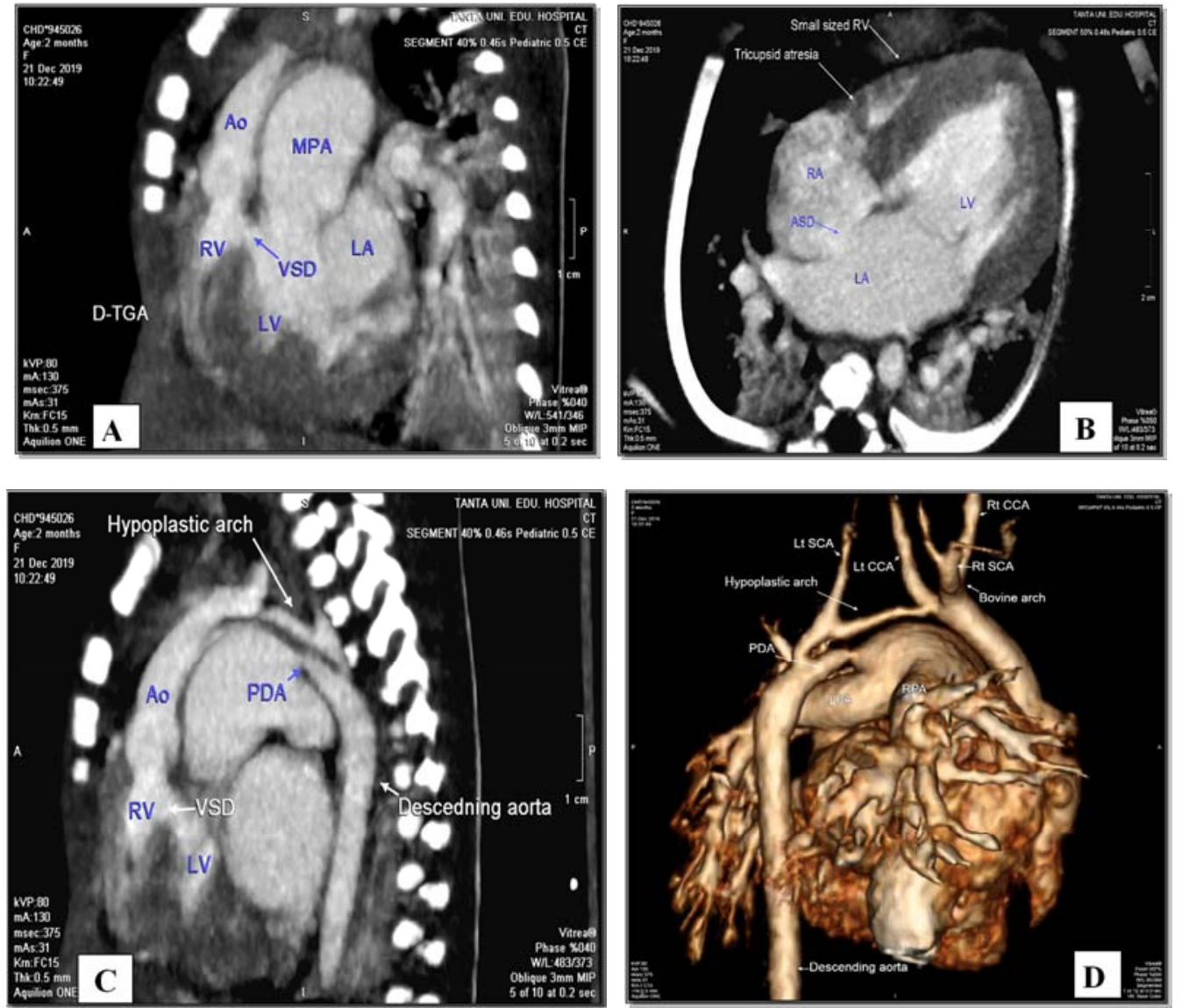

Figure 3. A case of transposition of the great arteries (D-TGA) aged 2 months presented with cyanosis and dyspnea.

(A) Oblique reformatted image showing anterior aorta arising from right ventricle, pulmonary artery originates from left ventricle and VSD.

(B) Oblique 4-Chamber view showing tricuspid atresia, ASD, Small sized right ventricle, dilated left atrium and left ventricle.

(C) MPR sagittal image showing PDA with wide aortic end and narrower pulmonary end, VSD and moderate tubular hypoplasia of aortic arch and aortic isthmus.

(D) VR image showing dilated MPA, moderate tubular hypoplasia of aortic arch and aortic isthmus and PDA.

\subsection{Case 4}

Female child aged 6 months presented with dyspnea.
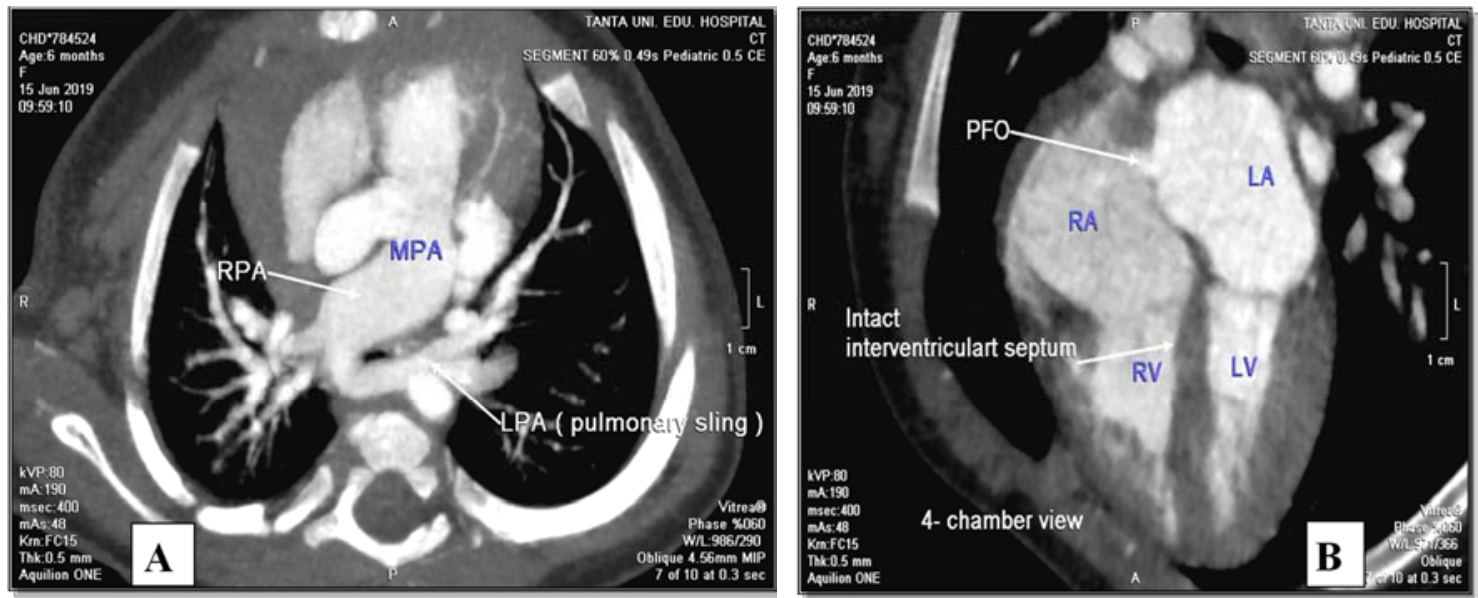

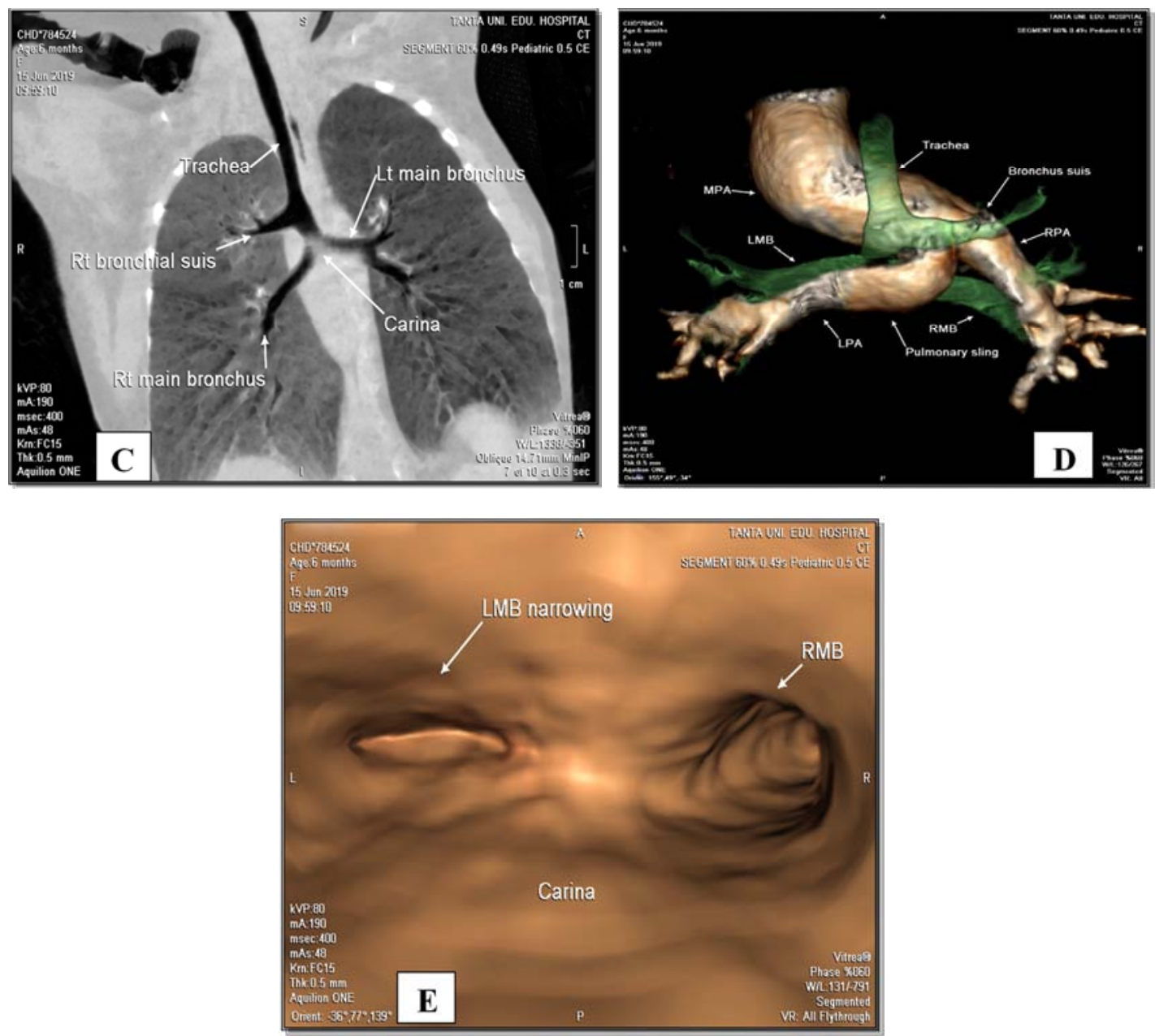

Figure 4. A case of left Pulmonary artery sling type IB.

(A) Axial MIP image showing anomalous origin of LPA from distal segment of RPA and encircling the trachea.

(B) Oblique 4-Chamber view showing patent foramen ovale ( $\mathrm{PFO}$ ) with bowing interatrial septum toward the right side.

(C) Coronal MinIP image shows a normal level of bronchial bifurcation and right bronchial suis.

(D) VR image shows the pulmonary tree with pulmonary sling with the LPA has anomalous origin from the RPA and encircle the distal end of trachea, carina and proximal segments of both mainstem bronchi with significant stenosis of the airways.

(E) Endoluminal image shows right main bronchus (RMB) and the compressed left main bronchus (LMB) by the pulmonary sling.

\subsection{Case 5}

Female child aged 5 days presented with cyanosis and tachypnea.
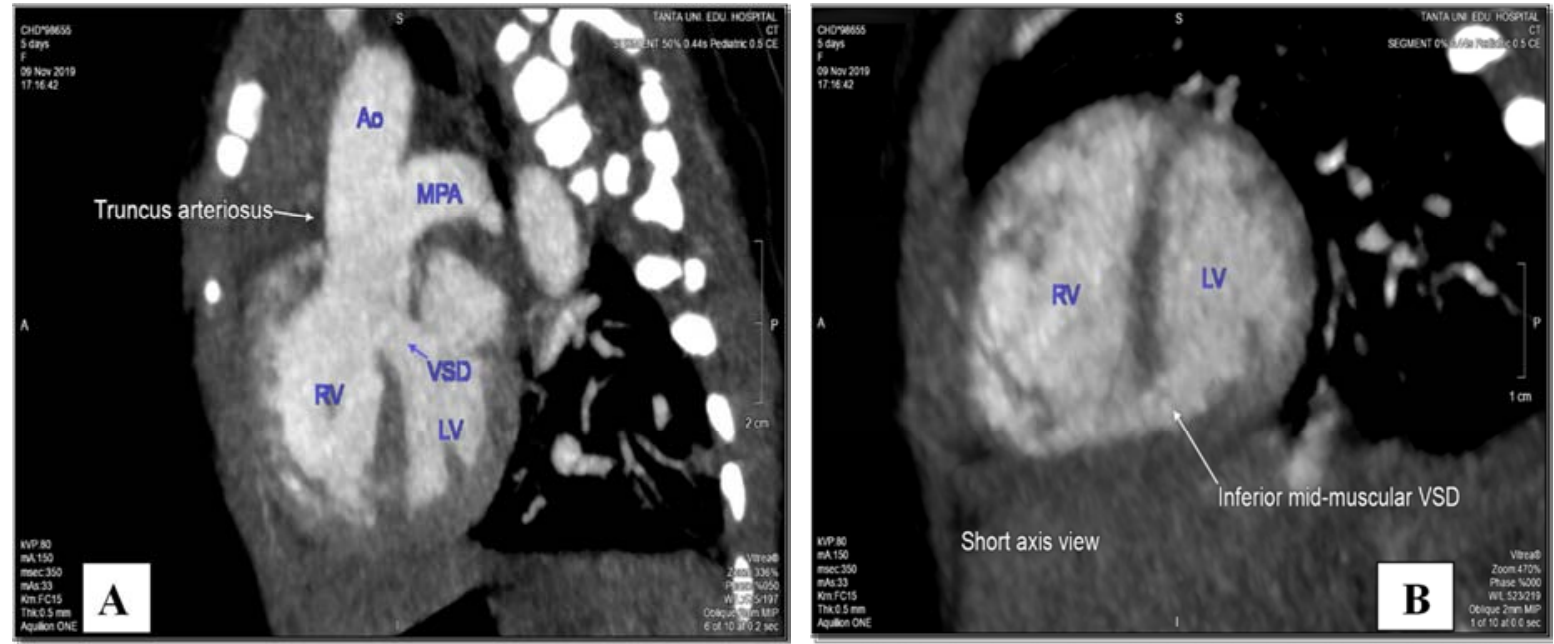

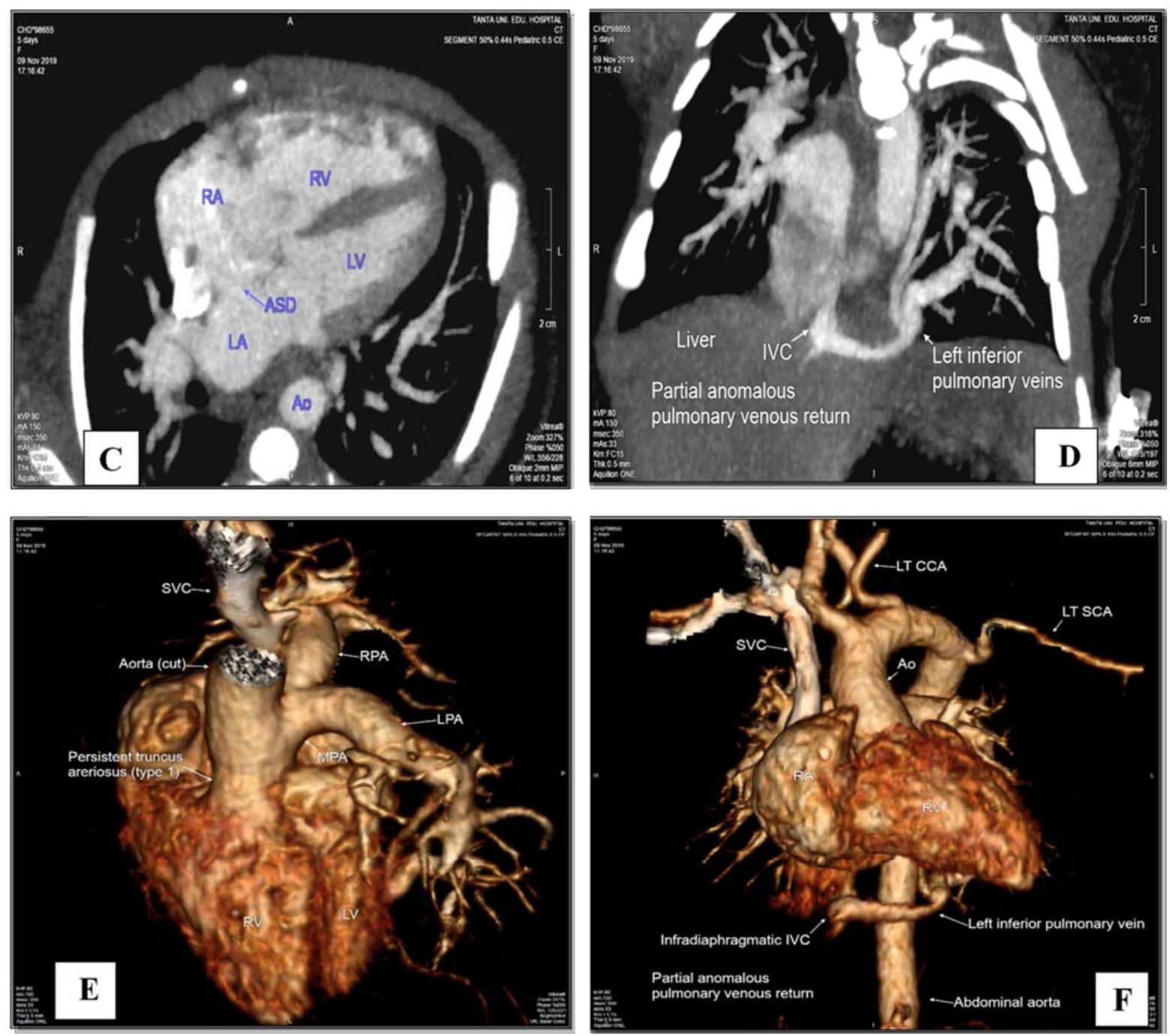

Figure 5. A case of truncus arteriosus type I associated with partial anomalous pulmonary venous return (PAPVR).

(A) Oblique sagittal reformatted image showing single atrial trunk overriding VSD with main pulmonary artery arising from left lateral side of truncus.

(B) Oblique Short axis view showing inferior mid-muscular VSD.

(C) Oblique 4-Chamber view showing ASD and dilated RA and RV.

(D) MPR coronal image showing PAPVR, the left inferior pulmonary veins drain into IVC just below diaphragmatic surface without obstruction

(E) VR image showing single arterial trunk (truncus arteriosus type I).

(F) VR image anterior view showing PAPVR, the left inferior pulmonary veins drain into IVC just below diaphragmatic surface.

\subsection{Case 6}

Male child aged 2 months presented with dyspnea and poor feeding.
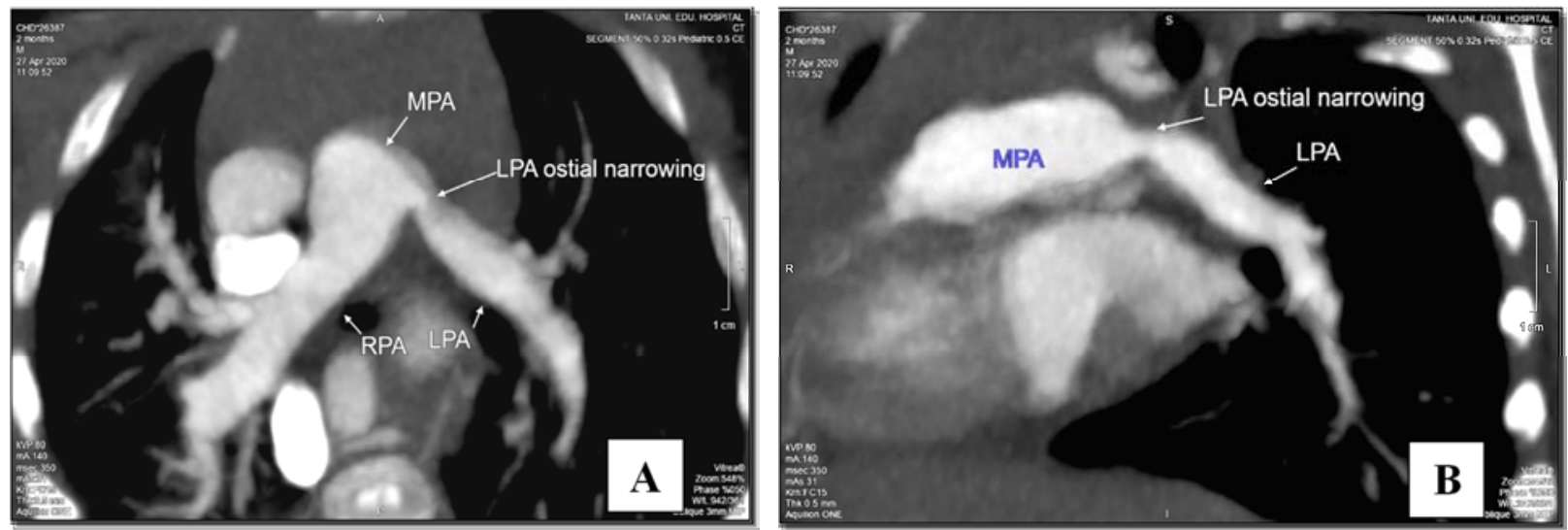

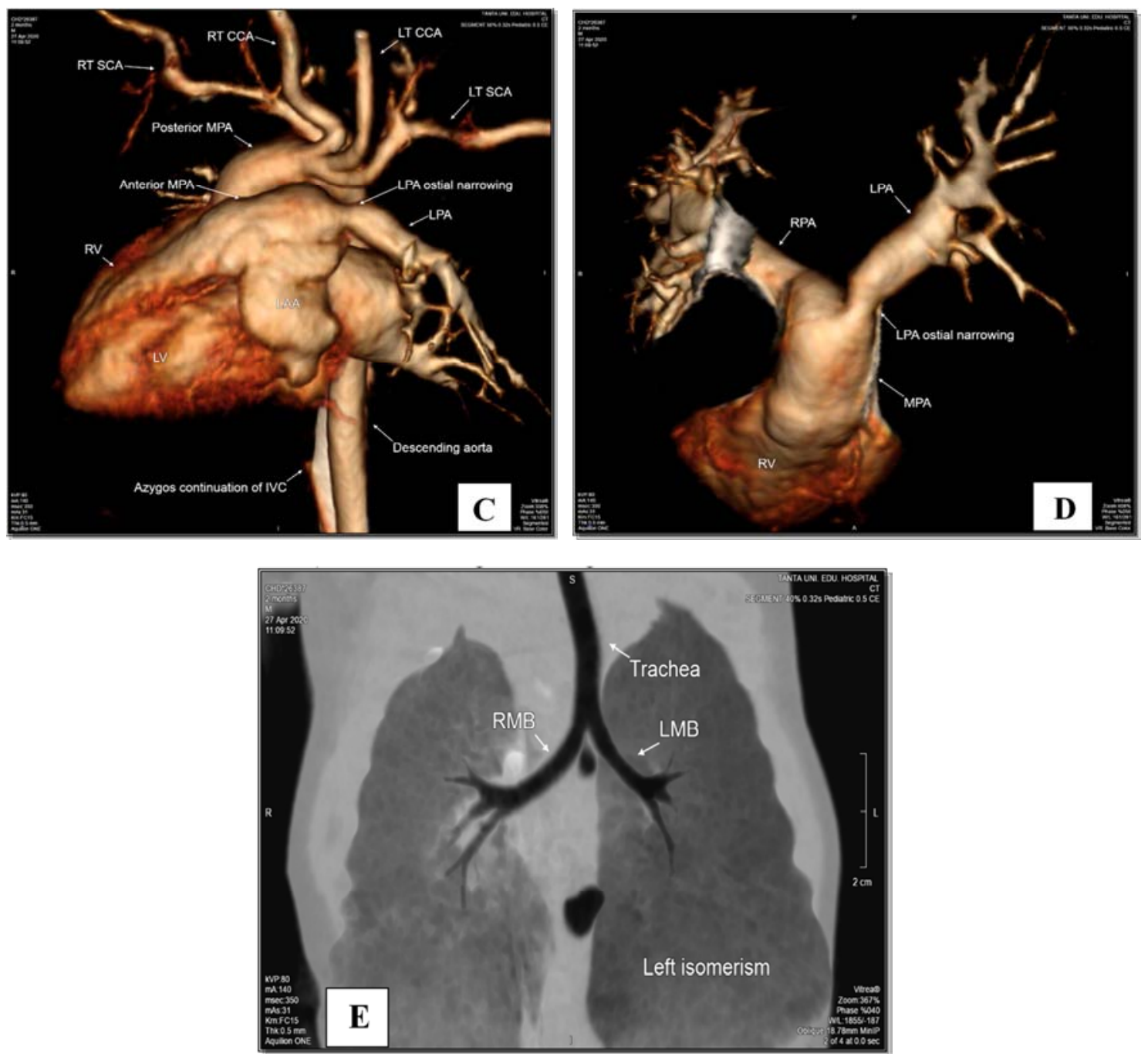

Figure 6. A case of Supravalvular pulmonary artery stenosis (type I) and situs ambiguous.

(A): Axial MIP image showing MPA, RPA and focal ostial stenosis of LPA.

(B) Oblique reconstructed MIP image showing MPA and focal ostial stenosis of LPA.

(C \&D) VR MIP image showing focal ostial stenosis of LPA.

(E) Coronal MinIP image showing left isomerism of right main bronchus (RMB).

\subsection{Case 7}

Male child aged 2 years with surgically corrected pulmonary atresia by valved conduit and VSD closure.
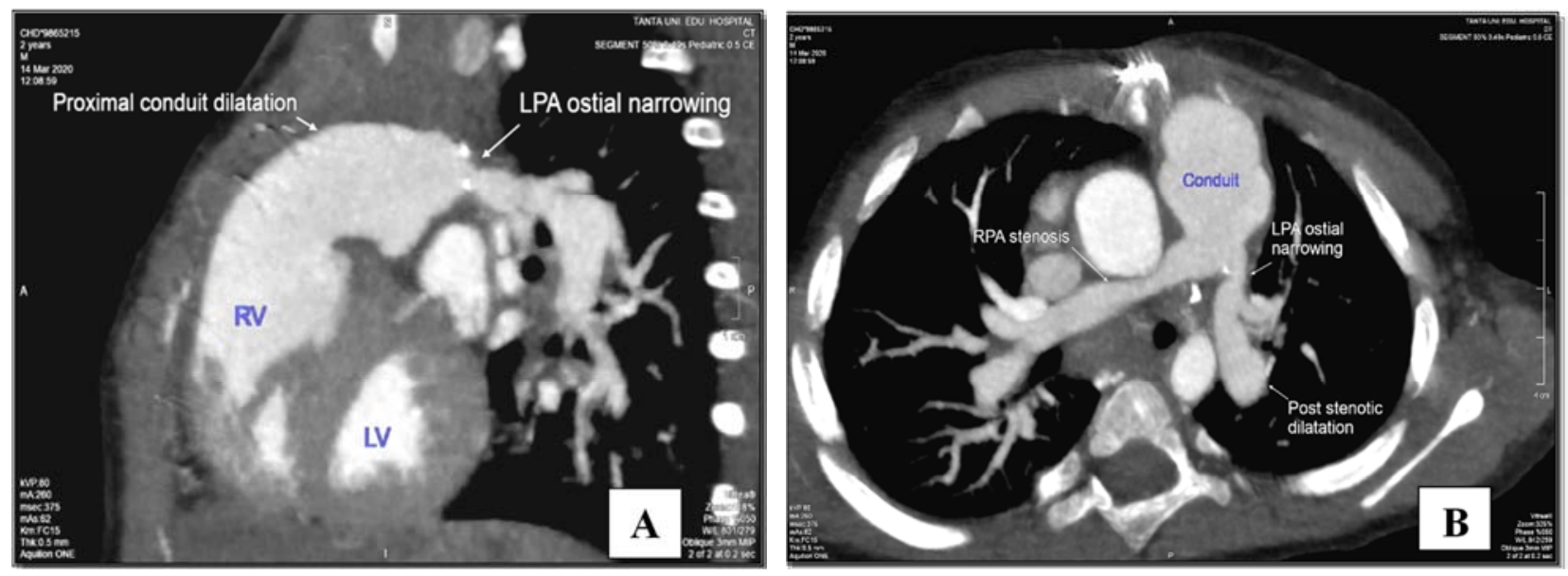

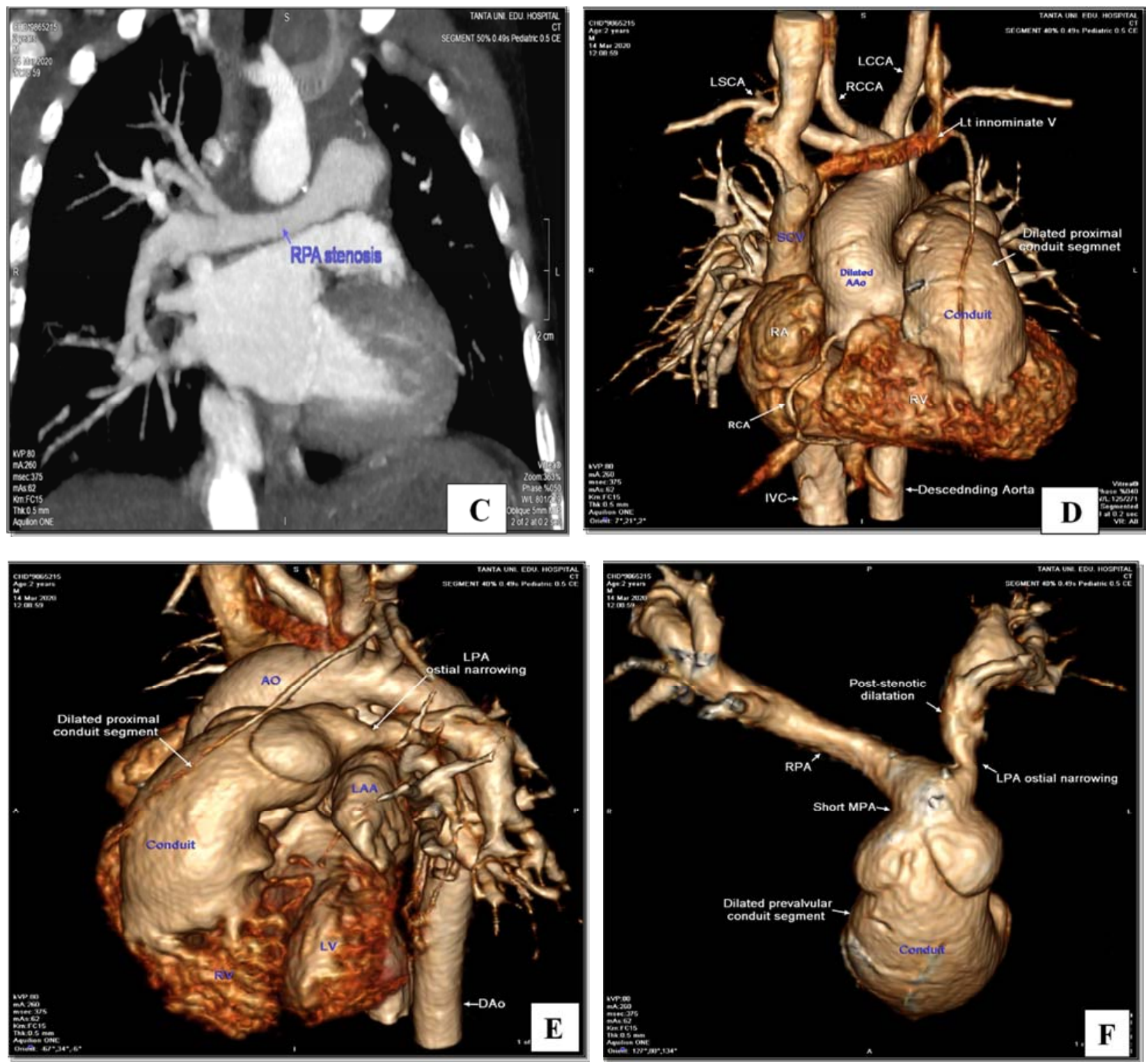

Figure 7. A case of surgically corrected pulmonary atresia by valved conduit with VSD closure.

(A) MPR sagittal image showing valved conduit and LPA ostial narrowing with post stenotic dilatation.

(B) Axial MIP image showing valved conduit, RPA stenosis and LPA ostial narrowing with post stenotic dilatation.

(C) Oblique reconstructed image showing RPA stenosis.

(D) Oblique 4-Chamber view showing intact interventricular image and hypertrophied RV wall.

(E) VR image showing valved conduit, dilated prevalvular conduit segment, LPA ostial narrowing and post stenotic dilatation.

(F) VR image showing valved conduit, dilated proximal conduit segment, LPA ostial narrowing and post stenotic dilatation.

\section{Discussion}

CT angiography (CTA) has an important value in the diagnosis of pediatric congenital heart diseases (CHD), also It can be used for the accurate post operative evaluation and in detection of complications [12]. CTA is useful for evaluation of most vascular pathology as it can illustrate anatomical details and is often the preferred non invasive imaging modality to get a detailed look at complex pulmonary arterial anatomy [2].

MSCT has a valuable role in diagnosis of pulmonary arterial anomalies through visualization of the main and branch pulmonary arteries, pulmonary confluence, presence of stenosis, major aorto-pulmonary collaterals, and patency of vascular shunts and conduits in children with previous surgeries [4].

In this study we studied role of MSCT as a diagnostic modality in assessment of pulmonary arterial anomalies including pathology, variants and associated intracardiac as well as extracardiac anomalies. We enrolled 76 patients (42 males and 34 females) with an age range between 4 days to 15 years. All patients included in this study were initially examined by echocardiography then by MSCT followed by cardiac catheterization or surgical repair in 38 cases.

In this study, 64 patients were sedated orally by choral hydrate (50-100 mg / kg; maximum dose, $2000 \mathrm{mg}$ ), only 6 
patients needed IV sedation using midazolam $(0.05-0.1 \mathrm{mg}$ $/ \mathrm{kg}$ ). Only older 6 patients were not sedated. Only verbal reassurance was adequate to carry on technique and they were able to completely suspend the respiration. No sedation related complications were encountered in the study. Singh et al., 2019 [13] reported that sedation was necessary in pediatrics to avoid motion artifact. They used $50-100 \mathrm{mg} / \mathrm{kg}$ of oral chloral hydrate in the majority of cases and they also used midazolam $(1 \mathrm{mg} / \mathrm{kg})$ in some patients.

Minimization of the radiation exposure delivered by CT is an important issue particularly for pediatrics. Lowering tube voltage or current is the direct way of achieving radiation dose reduction. Protocols using $80 \mathrm{kv}$ increase sensitivity to contrast medium by $50 \%$ compared to $120 \mathrm{kv}$ acquisitions. Low kv techniques favor safety issues on both side - contrast medium and radiation exposure and have been widely used in pediatric CT to reduce radiation exposure [14].

In the current study with a 320-slice scanner, we used ECG gated acquisition (retrospective gating) with low radiation dose protocol of $80 \mathrm{kV}$ in 70 patients and $100 \mathrm{kV}$ in 6 older patients with automatic adaptation of the mAs. The average dose length product was $91.79 \pm 88.45 \mathrm{mGy}-\mathrm{cm}$ and the effective radiation dose was $2.61 \pm 1.38$. This was significantly lower than a study by Bonelli-Sica et al., 2013 [15] who used 256 detectors computed tomography with ECG-gating with adapting dose parameters to body habitus and dose saving strategies; with the mean radiation dose was $(3.9 \mathrm{mSv})$. This may be attributed to the advantage of volumetric scanning over helical scanning in reducing the time of scanning and the radiation dose. And also, in another study by Lin et al., 2012 [16] who used 64 MDCT in their studies with the main of the effective dose reduction was 4.5 $\mathrm{mSv}$ and dose length product $115-218 \mathrm{mGy} \mathrm{cm}$ which is higher than by this study.

Al-Mousily et al., (2011) [17] who used prospective cardiac gating on a 320 -slice CT, their study reported more dose reduction to $0.8 \pm 0.39 \mathrm{mSv}$ and it is owing to use of prospective ECG gating which has the advantage of markedly reduced radiation exposure as the patient is irradiated only at selectable heart phases than the radiation used in this study in retrospective ECG gating.

In this study, male patients were more commonly presented with pulmonary arterial anomalies (42 males, $55.2 \%$ ) than female patients (34 females, $44.7 \%$ ) with a male to female ratio (1.2:1), their age ranged from the age of 4 days to 15 years. This came in agreement with Chandrashekhar et al., 2012 [4] who reported predominance of males than females in their study.

In the current study, the pulmonary artery anomalies were subclassified into 3 groups including anomalies of the caliber, origin and development (conotruncal anomalies).

Anomalies of the caliber include pulmonary atresia which is defined as lack of continuity between the right ventricle and the pulmonary arteries [18], pulmonary hypoplasia which can be diagnosed when there is diffuse narrowing involving long segment of the artery [12], pulmonary stenosis which is defined as the obstruction of flow from the right ventricle to the pulmonary arteries [18] and pulmonary dilatation, anomalies of the origin include pulmonary sling and the anomalies of development of MPA are the conotruncal anomalies which include (TOF, TGA, Congenitally corrected TGA, Truncus arteriosus and DORV).

In this study, MSCT declared that the most common anomaly of the MPA was the MPA atresia which diagnosed in (26 cases, 34.2\%), this came in agreement with Harraz et al., 2019 [12] who studied congenital pulmonary artery anomalies in pediatrics and reported also that the most common MPA anomaly was the MPA pulmonary atresia.

In contrast to Liu et al., (2013) [20] stated that pulmonary atresia is a rare pulmonary artery anomaly this disagreement may be due to because our hospital is considered a tertiary referral center for cases of congenital heart disease.

Regarding the main pulmonary artery, Chi square test revealed a non statistically significant difference between both Echo and MSCT in the detection of MPA anomalies. Regarding the pulmonary artery branches (RPA and LPA), Chi square test revealed a statistically significant difference between both ECHO and MSCT in their assessment $(\mathrm{p}=0.008)$. This came in agreement with Liu et al., (2016) [21] and Ali et al., (2020) [22] who declared that MDCT was much informative than ECHO which missed the diagnosis of pulmonary artery anomalies and other extracardiac vascular anomalies due to limited acoustic windows, low spatial resolution and structures are obscured by overlying bone and aerated lung.

Pulmonary artery stenosis is classified according to the level of the stenosis into subvalvular pulmonary stenosis, valvular pulmonary stenosis and supravalvular pulmonary stenosis [19].

In the present study we reported 24 cases with subvalvular type, 20 cases of valvular type and 20 cases of supravalvular type. In 20 cases we found more than a type of pulmonary stenosis.

Supravalvular pulmonary artery stenosis classified into several types: Type I is single central stenosis that could be noted at main, right, or left pulmonary artery, Type II there is stenosis seen at the bifurcation of the pulmonary arterial trunk involving the origins of the right and left Pas, Type III characterized by stenosis seen peripherally only and Type IV it is a mixed type when there is combined central and peripheral stenosis [23].

In the current study, we reported 20 cases with supravalvular pulmonary stenosis. The most common type of them was type I which represented $(90 \%)$ of cases of supra valvular pulmonary stenosis, this agreed with Abd El-Gaber, Alsawah, 2013 [24] who found also that type I is the most common of them. ECHO was unable to diagnose pulmonary artery stenosis in 9 patients owing to limited acoustic window and obscuration by aerated lung in ECHO.

Pulmonary atresia is classified into pulmonary atresia with ventricular septal defect (PA-VSD) and pulmonary atresia with intact interventricular septum (PA-IVS) [25].

A practical classification of pulmonary atresia-VSD has been proposed by Congenital Heart Surgeons Society based on complexity of pulmonary blood supply which in turn 
indicates the complexity of surgical repair: Type A: Native pulmonary arteries present, pulmonary vascular supply through PDA and no MAPCs, (ductal dependent pulmonary circulation), Type B: Native pulmonary arteries and MAPCs present (MAPCAS dependent pulmonary circulation) and Type C: No native PAs, pulmonary blood supply through MAPCs only [26].

In our study we reported 20 cases of pulmonary atresia with (type A) duct dependent pulmonary circulation and 4 cases of (type B) pulmonary atresia with MAPCAS dependent pulmonary circulation.

McGoon ratio is a method to evaluate the size of pulmonary artery branches by measuring the summation of right and left pulmonary artery diameter at the point before its branching, divided by the diameter of the descending aorta at the level of the diaphragm. The normal range of the ratio is $(2-2.5)$ [27]. If it is more or equal to 1.2 then it is favorable for complete repair and if it is less than 0.8 then it is inadequate for complete repair [28].

In this study, McGoon ratio simply calculated in all cases of small sized main pulmonary artery or its two major branches in (46 cases) using oblique view for evaluation of pulmonary branches. Out of the 46 cases, the Mcgoons ratio was favorable in (32 patients, $69.6 \%$ ) so this group of patients were adequate for complete surgical repair. This came is agreement with Mohan et al., 2013 [29] who also calculated the McGoon ratio in the cases of small pulmonary arteries and declared its importance for evaluation of the case before any operative interference.

Truncus arteriosus is a single arterial trunk with a single semilunar valve that gives origin to the aorta, pulmonary artery, and the coronary arteries. The van Praagh classification divides truncus arteriosus with VSD (Type A) into four types. In Type A1, a common arterial trunk for aorta and main pulmonary artery ; in Type A2, no MPA present, and separate origin of right and left central branch PAs from the posterior or posterolateral proximal common trunk; in Type A3, origin of one central PA branch (usually right) from the proximal common trunk while the opposite lung is supplied by a central branch PA originate from the aortic arch (ductal origin) or aortopulmonary collateral supply; in Type A4, there is interrupted aortic arch with Types 1 or 2 PA branching and a ductus arteriosus supplying the descending aorta [25].

In this study, we detected 4 cases of truncus arteriosus type I according to van Praagh classification. This came in agreement with Harraz et al., 2019 [12], who reported also only 2 cases of type I.

In this study, we detected one case of truncus arteriosus type I is associated with PAPVR whereas the left inferior pulmonary vein drains into IVC and this disagrees with Abd El-Gaber, Alsawah, 2013 [27], who stated that truncus arteriosus is usually an isolated finding, and the 2 cases detected in their study didn't have any associated anomalies.

Bajolle et al., (2009) [26], studied conotruncal anomalies association with anomalous pulmonary venous connections and reported 7 cases of truncus arteriosus that associated with anomalous pulmonary venous return and one case of them was associated with PAPVR to IVC and this came in agreement with the current study.

In the current study, MSCT diagnosed 10 cases of D-TGA and 4 cases of L-TGA. Zhang et al., 2013 [30], declared that MDCT has high accuracy and a great role in the diagnosis of the cases with TGA as their study diagnosed all cases of TGA correctly by 64-MDCT.

In the present study, MSCT reported 39 cases of PDA $(41.3 \%)$ and 10 cases $(10.9 \%)$ of MAPCAs. This came in agreement with Alam et al ,.2019 [31] their study revealed predominance of PDA which was 56 cases associated with other anomalies followed by MAPCAs in 13 cases.

ECHO missed detection of 6 cases of PDA and 8 cases of MAPCAs and this came in agreement with Hu et al., 2017 [32] who stated that ECHO can only identify relatively large ones, but hardly identify the ones originating from the descending aorta whereas the number, origin, and caliber of MAPCAs could be visualized on MDCT that is important for the evaluation of the case.

Pulmonary artery sling is a rare vascular anomaly causing respiratory distress in which the left pulmonary artery originates from the right pulmonary artery which courses between the trachea and esophagus toward the left hilum [25].

In this study, we diagnosed two cases of pulmonary sling causing significant air way narrowing while ECHO missed the detection of them. Nie et al., (2014) [33], also reported that ECHO missed diagnosis of 4 cases of pulmonary sling.

Leonardi et al., (2015) [34], declared that CT has an important role in the management of pulmonary sling and determination of the surgical strategy as it provides information about the pulmonary artery course, tracheobronchial tree and the relation between the pulmonary artery and trachea.

The accuracy of MSCT was evaluated, correlated and compared with operative findings or cardiac catheterization as the golden standard for the diagnosis of pulmonary arterial anomalies. Out of the 76 cases, we followed 38 cases of them as some cases died before the surgical intervention and others missed to be followed.

MSCT is an important non-invasive modality for accurate diagnosis of our pulmonary artery anomalies cases; MSCT could diagnose cases of pulmonary arterial anomalies with $99 \%$ sensitivity, 99.8\% specificity, 99\% PPV, 99.8\% NPV and 93.4\% accuracy. The missed anomalies by MSCT were due to cardiac motion artifact which affected the quality of the examination. $\mathrm{Bu}$ et al., (2016) [35], also declared that MSCT has a great role in diagnosis of pulmonary arterial anomalies and other great vessel malformations when their results correlated also with surgical findings.

In this study, MSCT detected the extracardiac anomalies and identify the tracheobronchial branching, the eparterial/ hyparterial position of bronchi, detect visceral heterotaxy syndrome and visceral malposition. This came in agreement with Kahtri et al., 2009 [36] who reported also the great role of $\mathrm{CT}$ in evaluating the extracardiac structures.

In this study, regarding the VSD MSCT missed detection of 1 case of membranous VSD and 2 cases of ASD however, Chi 
square test revealed non-statistically significant difference between Echo and $\mathrm{CT}$ in the detection of intracardiac anomalies as this used ECG gated technique which improves the quality of MSCT in detection of intracardiac anomalies. Abd El-Gaber, Alsawah, 2013 [24], missed diagnosis of more cases of intracardiac anomalies owing to usage of non ECG gated technique.

\section{Conclusion}

MSCT is a non-invasive accurate imaging modality that has a significant value in the evaluation of congenital pulmonary artery anomalies and their associated extracardiac anomalies in pediatric patients as well as the assessment of post-operative complications. It is superior to ECHO in evaluating the pulmonary artery anomalies specially the pulmonary artery branches which are obscured by the aerated lung. Also, there is a good outcome of the cases owing to early and accurate diagnosis of the cases and post-operative follow up.

\section{Abbreviation}

$\mathrm{CTA}=$ Computed tomography angiography, $\mathrm{MSCT}=\mathrm{Multi}$ slice computed tomography, MDCT=Multi detector computed tomography $\mathrm{ECHO}=$ Echocardiography, $\quad \mathrm{CT}=$ Computed tomography, $\mathrm{PAs}=$ Pulmonary arteries, $\mathrm{MPA}=$ main pulmonary artery, RPA=Right pulmonary artery, LPA=Left pulmonary artery, $\mathrm{PA}-\mathrm{VSD}=$ pulmonary atresia with ventricular septal defect, PA-IVS=Pulmonary atresia with intact interventricular septum, TOF=Tetralogy of Fallot, TGA=Transposition of the great arteries, DORV=Double outlet right ventricle, MAPCAs=Major aortopulmonary collateral arteries, $\mathrm{PDA}=$ Patent ductus arteriosus, $\mathrm{ASD}=$ Atrial septal defect, $\mathrm{VSD}=$ Ventricular septal defect, $\mathrm{PFO}=$ patent foramen ovale, $\mathrm{MPR}=$ Multiplanar reconstruction, $\mathrm{MIP}=$ Minimum intensity projection, MinIP $=$ Minimum intensity projection, $\mathrm{VR}=$ Volume rendered. Sen $=$ Sensitivity, $\mathrm{Spec}=$ Specificity, $\mathrm{PPV}=$ Positive predictive value, NPV=Negative predictive value, Acc $=$ Accuracy

\section{References}

[1] Dimas VV, Dillenbeck J, Josephs S.(2018) Congenital pulmonary vascular anomalies. Cardiovasc Diagn Ther.; 8 (3): 214-224.

[2] Marini, T. J., He, K., Hobbs, S. K., \& Kaproth-Joslin, K. (2018). Pictorial review of the pulmonary vasculature: from arteries to veins. Insights into Imaging, 9 (6), 971-987.

[3] Orwat S, Diller GP, Baumgartner H.(2014) Imaging of congenital heart disease in adults: Choice of modalities. Eur Heart J Cardiovasc Imaging., 15 (1): 6-17.

[4] Chandrashekhar G, Sodhi KS, Saxena AK, et al.(2012) Correlation of 64 row MDCT, echocardiography and cardiac catheterization angiography in assessment of pulmonary arterial anatomy in children with cyanotic congenital heart disease. 81 (12): 4211-4217.

[5] Dis., Raimondi F and Warin-Fresse K. (2016) Computed tomography imaging in children with congenital heart disease: Indications and radiation dose optimization. Arch Cardiovasc and 109 (2): 150-157.

[6] Roentgenol., Dillman JR and Hernandez RJ. (2009) Role of CT in the evaluation of congenital cardiovascular disease in children. Am J and , 192 (5): 1219-1231.

[7] Bhalla, S., Javidan-Nejad, C., Bierhals, A. J., Woodard, P. K., \& Gutierrez, F. R. (2008). CT in the evaluation of congenital heart disease in children, adolescents, and young adults. Current treatment options in cardiovascular medicine, 10 (5), 425-432.

[8] Lee, E. Y., Boiselle, P. M., \& Shamberger, R. C. (2010). Multidetector computed tomography and 3-dimensional imaging: preoperative evaluation of thoracic vascular and tracheobronchial anomalies and abnormalities in pediatric patients. Journal of pediatric surgery, 45 (4), 811-821.

[9] Ntsinjana HN, Hughes ML, Taylor AM. (2011) The role of cardiovascular magnetic resonance in pediatric congenital heart disease. J Cardiovasc Magn Reson.; 13 (1): 1-20.

[10] Prakash A, Powell AJ, Geva T. (2010) Multimodality noninvasive imaging for assessment of congenital heart disease. Circ Cardiovasc Imaging. 2010; 3 (1): 112-125.

[11] Duan, Y., Wang, X., Cheng, Z., Wu, D., \& Wu, L. (2012). Application of prospective ECG-triggered dual-source CT coronary angiography for infants and children with coronary artery aneurysms due to Kawasaki disease. The British journal of radiology, 85 (1020), e1190-e1197.

[12] Harraz MM, Abouissa AH, Saleh HA, Attas KA, Al-Yamani SM, Alsulami G, Refai MM.(2019) MDCT angiographic findings of various congenital pulmonary artery anomalies in pediatric patients. Egyptian Journal of Radiology and Nuclear Medicine. 1; 50 (1): 94.

[13] Singh RK, Jain N, Kumar S, Garg N. (2019) Multi-detector computed tomography angiographic evaluation of right ventricular outflow tract obstruction and other associated cardiovascular anomalies in tetralogy of Fallot patients. Polish Journal of Radiology.; 84: e 511-516.

[14] McCollough, C. H., Primak, A. N., Braun, N., Kofler, J., Yu, L., \& Christner, J. (2009). Strategies for reducing radiation dose in CT. Radiologic Clinics, 47 (1), 27-40.

[15] Bonelli-Sica, J. M., Mora-Cervantes, R. D. L., Diaz-Zamudio, M., Castillo-Castellon, F., Ramirez-Carmona, R., Velazquez-Moreno, J., \& Kimura-Hayama, E. (2013). Dual-source 256-MDCT for diagnosis of anomalous pulmonary venous drainage in pediatric population. American Journal of Roentgenology, 200 (2), W163-W169.

[16] Lin, M. T., Wang, J. K., Chen, Y. S., Lee, W. J., Chiu, H. H., Chen, C. A.,... \& Chen, S. J. (2012). Detection of pulmonary arterial morphology in tetralogy of Fallot with pulmonary atresia by computed tomography: 12 years of experience. European journal of pediatrics, 171 (3), 579-586.

[17] Al-Mousily, F., Shifrin, R. Y., Fricker, F. J., Feranec, N., Quinn, N. S., \& Chandran, A. (2011). Use of 320-detector computed tomographic angiography for infants and young children with congenital heart disease. Pediatric cardiology, 32 (4), 426-432. 
[18] Escalon, J. G., Browne, L. P., Bang, T. J., Restrepo, C. S., Ocazionez, D., \& Vargas, D. (2019). Congenital anomalies of the pulmonary arteries: an imaging overview. The British journal of radiology, 92 (1093), 20180185.

[19] Hirsig, L. E., Sharma, P. G., Verma, N., \& Rajderkar, D. A. (2018). Congenital pulmonary artery anomalies: a review and approach to classification. Journal of clinical imaging science, 8.

[20] Liu, B., Monroe, E. J., \& Kogut, M. J. (2013). Proximal interruption of the pulmonary artery: transcatheter embolization for emergent management of massive hemoptysis Radiology case reports, 8 (3), 865.

[21] Liu, J., Li, H., Liu, Z., Wu, Q., \& Xu, Y. (2016). Complete preoperative evaluation of pulmonary atresia with ventricular septal defect with multi-detector computed tomography. PloS one, 11 (1), e0146380.

[22] Ali, S. A., Amin, D. H., \& Khattab, R. T. (2020). Intermodality agreement between TTE and low kVp ECG-gated MDCTA in diagnosis of complex CHD in pediatrics. Egyptian Journal of Radiology and Nuclear Medicine, 51 (1), 1-11.

[23] Maldonado, J. A., Henry, T., \& Gutiérrez, F. R. (2010). Congenital thoracic vascular anomalies. Radiologic Clinics, 48 (1), 85-115.

[24] Abd El-Gaber, N., \& Alsawah, G. A. (2013). Role of 16-multidetector CT angiography in assessment of arterial and venous pulmonary anomalies in pediatrics. The Egyptian Journal of Radiology and Nuclear Medicine, 44 (3), 483-495.

[25] Newman, B., \& Alkhori, N. (2020). Congenital central pulmonary artery anomalies: Part 2. Pediatric Radiology, 1-11.

[26] Rajeshkannan, R., Moorthy, S., Sreekumar, K. P., Ramachandran, P. V., Kumar, R. K., \& Remadevi, K. S. (2010). Role of 64-MDCT in evaluation of pulmonary atresia with ventricular septal defect. American Journal of Roentgenology, 194 (1), 110-118.

[27] Sirichongkolthong, B. (2018). Correlation Between Aortic Oxygen Saturation and Pulmonary Artery Size in Cyanotic Congenital Heart Disease With Decreased Pulmonary Blood Flow. Ramathibodi Medical Journal, 41 (3), 21-29.
[28] Mohan, A., Balat, H., Vaghela, D., Ninama, G., Balat, J., \& Damor, S. (2013). Study of role of MDCT in pulmonary angiography in evaluation of pulmonary arteries patterns in children with tetralogy of Fallot. Int J Res Med, 2, 13-16.

[29] Bajolle, F., Zaffran, S., Losay, J., Ou, P., Buckingham, M., \& Bonnet, D. (2009). Conotruncal defects associated with anomalous pulmonary venous connections. Archives of cardiovascular diseases, 102 (2), 105-110.

[30] Zhang, Y., Hua, S., Liu, Y., Gao, J., Liu, J., Liu, S.,... \& Hao, P. (2013). Usage of 64-slice CT in the diagnosis of congenital cardiovascular malformations. Life Science Journal, 10 (2), $1-5$.

[31] Alam, T., Munir, M. K., \& Hamidi, H. (2019). Congenital heart disease frequency in children undergoing MDCT angiography; a 4-year tertiary care hospital experience from Kabul, Afghanistan. BJR| Open, 1 (1), 20180032.

[32] Hu, B. Y., Shi, K., Deng, Y. P., Diao, K. Y., Xu, H. Y., Li, R.,... \& Guo, Y. K. (2017). Assessment of tetralogy of Fallotassociated congenital extracardiac vascular anomalies in pediatric patients using low-dose dual-source computed tomography. BMC Cardiovascular Disorders, 17 (1), 1-8.

[33] Nie, P., Yang, G., Wang, X., Duan, Y., Xu, W., Li, H.,... \& Wang, A. (2014). Application of prospective ECG-gated high-pitch 128-slice dual-source CT angiography in the diagnosis of congenital extracardiac vascular anomalies in infants and children. PLoS One, 9 (12), 1-14. e115793.

[34] Leonardi, B., Secinaro, A., Cutrera, R., Albanese, S., Trozzi, M., Franceschini, A., \& Pongiglione, G. (2015). Imaging modalities in children with vascular ring and pulmonary artery sling. Pediatric pulmonology, 50 (8), 781-788.

[35] Bu, G., Miao, Y., Bin, J., Deng, S., Liu, T., Jiang, H., \& Chen, W. (2016). Comparison of 128-Slice low-dose prospective ECG-gated CT scanning and trans-thoracic echocardiography for the diagnosis of complex congenital heart disease. PloS one, 11 (10), 1-12 e0165617.

[36] Khatri, S., Varma, S. K., Khatri, P., \& Kumar, R. S. (2008). 64-slice multidetector-row computed tomographic angiography for evaluating congenital heart disease. Pediatric cardiology, 29 (4), 755-762. 